\title{
ORIGINAL ARTICLE \\ Landscape features and helminth co-infection shape bank vole immunoheterogeneity, with consequences for Puumala virus epidemiology
}

\author{
E Guivier ${ }^{1}, \mathrm{M}$ Galan $^{1}, \mathrm{H}$ Henttonen ${ }^{2}, \mathrm{~J}-\mathrm{F}$ Cosson $^{1}$ and N Charbonnel ${ }^{1}$ \\ Heterogeneity in environmental conditions helps to maintain genetic and phenotypic diversity in ecosystems. As such, it may \\ explain why the capacity of animals to mount immune responses is highly variable. The quality of habitat patches, in terms of \\ resources, parasitism, predation and habitat fragmentation may, for example, trigger trade-offs ultimately affecting the \\ investment of individuals in various immunological pathways. We described spatial immunoheterogeneity in bank vole \\ populations with respect to landscape features and co-infection. We focused on the consequences of this heterogeneity for the \\ risk of Puumala hantavirus (PUUV) infection. We assessed the expression of the Tnf- $\alpha$ and $M \times 2$ genes and demonstrated a \\ negative correlation between PUUV load and the expression of these immune genes in bank voles. Habitat heterogeneity was \\ partly associated with differences in the expression of these genes. Levels of $M \times 2$ were lower in large forests than in \\ fragmented forests, possibly due to differences in parasite communities. We previously highlighted the positive association \\ between infection with Heligmosomum mixtum and infection with PUUV. We found that Tnf- $\alpha$ was more strongly expressed in \\ voles infected with PUUV than in uninfected voles or in voles co-infected with the nematode H. mixtum and PUUV. H. mixtum \\ may limit the capacity of the vole to develop proinflammatory responses. This effect may increase the risk of PUUV infection \\ and replication in host cells. Overall, our results suggest that close interactions between landscape features, co-infection and \\ immune gene expression may shape PUUV epidemiology.
}

Heredity (2014) 112, 274-281; doi:10.1038/hdy.2013.103; published online 23 October 2013

Keywords: Myodes glareolus; hantavirus; helminth; Mx2; Tnf- $\alpha$; landscape immunogenetics

\section{INTRODUCTION}

The ability to mount immune responses varies strongly between individuals in natural populations. Understanding the maintenance of this variation, despite its apparent disadvantage in terms of host fitness, has been at the core of immunoecology for three decades (Sheldon and Verhulst, 1996; Lazzaro and Little, 2009). It is now widely recognized that immunoheterogeneity results from an interplay between evolutionary and proximate causes, including host-parasite coevolution (Woolhouse et al., 2002), life history (Schmid-Hempel, 2003), immunological and physiological tradeoffs (Schmid-Hempel, 2003; Cotter et al., 2004) or phenotypic plasticity (Bocher et al., 2007).

Landscape, which may be defined as an area of land containing a mosaic of habitat patches, has been identified as a potentially key factor shaping spatial immunoheterogeneity. Habitat patches vary in quality, in terms of resources, intensities of predation, parasitism and competition, and microclimate conditions. All these features may affect the outcomes of trade-offs, through plastic responses or natural selection (for a review, see Schulenburg et al., 2009).

Multiparasitism may modulate the extent to which the organism invests in immunity as opposed to other life history traits (for example, Bordes and Morand, 2009) and the outcomes of immunological trade-offs (Cox, 2001; Graham et al., 2007). In vertebrates, the most heated debates have concerned the T helper-1 immune pathway, which is involved principally in the response to intracellular infections (for example, with viruses), and the $\mathrm{T}$ helper-2 immune pathway, which regulates infections with extracellular parasites, such as helminths (for a review, see Kidd, 2003). Several studies have provided evidence that helminth infections modulate the $\mathrm{T}$ helper$1 / \mathrm{T}$ helper-2 balance, thereby increasing susceptibility to viral (see reviews Kamal and El Sayed Khalifa, 2006; Graham, 2008), bacterial (Pathak et al., 2012) or malarial (Knowles, 2011) infections. The landscape features may affect these patterns of multiparasitism by influencing the composition, diversity and structure of pathogen communities (for example, for helminths or microbial communities Koopman and Carstens, 2011; Ribas Salvador et al., 2011).

The spatial arrangement of habitat patches, their fragmentation and connectivity have been shown to have a large effect on the size and migration rate of populations living in these environments. Habitat fragmentation and connectivity determine the relative influence of drift and gene flow, potentially modifying the levels and distribution of host and parasite genetic variability. Low levels of genetic diversity may be observed in small, isolated host populations, ultimately leading to inbreeding depression and a lower capacity to mount immune responses (Rantala et al., 2011) or higher susceptibility to parasitism (Whitehorn et al., 2011). The spatial

IINRA, UMR CBGP (INRA/IRD/Cirad/Montpellier SupAgro), Campus international de Baillarguet, Montferrier-sur-Lez cedex, France and 2Finnish Forest Research Institute, Vantaa, Finland

Correspondence: Dr N Charbonnel, UMR CBGP, Campus international de Baillarguet, CS 30016, F-34988 Montferrier-sur-Lez cedex, France.

E-mail: nathalie.charbonnel@supagro.inra.fr

Received 17 May 2013; revised 9 September 2013; accepted 16 September 2013; published online 23 October 2013 
arrangement of habitat patches and heterogeneity in abiotic/biotic factors, by influencing host metapopulation dynamics and the outcomes of host-parasite interactions, thus appear to be key determinants of immune gene variability.

In this study, we investigated the influence of landscape features and co-infection on the spatial immunoheterogeneity of wild bank vole populations (Myodes glareolus). We analyzed the contribution of these parameters to the variability in immune gene expression. We then investigated whether these parameters also affected the epidemiology of a virus carried specifically by the bank vole, Puumala hantavirus (PUUV, family Bunyaviridae genus Hantavirus), which causes nephropathia epidemica, a mild form of hemorrhagic fever with a renal syndrome, in humans.

We addressed these questions by studying bank vole populations sampled in the French Ardennes, a region in which nephropathia epidemica is endemic (Vapalahti et al., 2003). This region is characterized by patches of continuous forests and fragmented habitats of varying qualities (see details in Heyman et al., 2009). The metapopulation dynamics of bank voles settled in this heterogeneous landscape and its potential impact on PUUV epidemiology has previously been described (Guivier et al., 2011). Bank vole populations established in large forests exhibit large effective size, experience important gene flow and are weakly subject to genetic drift (Guivier et al., 2011). This dynamics seems to facilitate the maintenance and spread of PUUV in this landscape, as shown by the higher prevalence levels observed in this habitat. By contrast, vole populations settled in fragmented wooded areas, including hedge networks, are of smaller effective size and are more strongly affected by stochastic processes such as extinction and recolonization. This dynamics is one of the potential factors that prevent the persistence of PUUV in these populations (Guivier et al., 2011). We have also shown that some landscape features affect the gastrointestinal helminth communities of these bank vole populations (Ribas Salvador et al., 2011). In particular, we have highlighted the higher prevalence of PUUV and of concomitant infections with PUUV and the nematode Heligmosomum mixtum in the northern part of this region (the 'massif des Ardennes'). We therefore hypothesized that landscape features might drive spatial immunoheterogeneity through virus/ helminth co-infections and metapopulation dynamics.

Our ultimate aim was to explore the potential links between immune variation and PUUV epidemiology. We therefore evaluated immunoheterogeneity by focusing on the expression of genes encoding molecules involved in the response to PUUV infection. M. glareolus is the main specific reservoir of PUUV in the wild. Transmission between bank voles is exclusively horizontal and is mediated by the inhalation of infected aerosols or aggressive behavior (see a review in Schonrich et al., 2008). Infection with this virus is considered to be chronic (Meyer and Schmaljohn, 2000). Voles experience a transient period of viremia, beginning a few days after infection and peaking 2-4 weeks post-infection (Hardestam et al., 2008), although viral RNA has been detecting 84 days post-infection in some experimentally infected bank voles. Periodic episodes of viral recrudescence may occur during the lifetime of the vole, because of changes in the virus and/or host immune response (Hardestam et al., 2008). Besides, anti-hantavirus immunoglobulin G are usually detectable 2 weeks after infection and seems to remain detectable for the lifetime of the rodents (see references in Easterbrook and Klein, 2008).

PUUV infection in $M$. glareolus has been described as asymptomatic (Yanagihara et al., 1985), but a small impact on fitness has been reported (Tersago et al., 2012). Field surveys and laboratory experiments have indicated that the probability of infection with PUUV differs between individual bank voles, which also differ in their response to PUUV infection (Olsson et al., 2002; Kallio et al., 2006; Hardestam et al., 2008; Deter et al., 2008b; Guivier et al., 2010a). Polymorphism and variability in the expression of immune genes may determine the ability of the vole to control hantavirus replication (Plyusnin et al., 1997; Makela et al., 2002; Klein et al., 2004; Terajima et al., 2004).

We focused on the proinflammatory cytokine tumor necrosis factor- $\alpha(\mathrm{TNF}-\alpha)$ and the antiviral protein Mx2. These molecules limit PUUV replication in humans and in cell cultures (Kanerva et al., 1996; Temonen et al., 1996; Jin et al., 2001). The overproduction of these molecules also leads to pathological symptoms ( $\mathrm{Li}$ and Youssoufian, 1997; Wenzel et al., 2005; Porter et al., 2006; Bradley, 2008). We analyzed the variability of Tnf- $\alpha$ and $M \times 2$ gene expression between individuals, populations and habitat patches. We first investigated the constitutive (non-induced) effects of $\operatorname{Tnf}-\alpha$ and Mx2 gene expression levels on PUUV viral load. Negative impacts would confirm the implication of these immune genes in the inhibition of PUUV replication. We then investigated the effects of habitat heterogeneity on the levels of expression of the Tnf- $\alpha$ and $M \times 2$ genes. We hypothesized that these genes would be more weakly expressed in hedges, which are considered to be lower quality habitats, in which less costly immune responses might be favored. Finally, we investigated whether $H$. mixtum infection was an important additional source of immunoheterogeneity in bank voles and we analyzed its potential interaction with the risk of PUUV infection.

\section{MATERIALS AND METHODS}

\section{Vole sampling and parasitological screening}

Bank voles were trapped in the French Ardennes from the 1st of September to the 7th of October 2008, along a transect of about $80 \mathrm{~km}$ corresponding to a gradient of nephropathia epidemica cases. Along this transect, we sampled six sites in forested areas (three in the northern 'massif des Ardennes' and three in the southern 'crêtes ardennaises') and four sites in fragmented habitats (hedge networks). Trapping results are detailed in Supplementary Table S1. Animals were killed by cervical dislocation, as recommended by Mills et al. (1995). They were weighed, sexed and dissected. Sexual maturity was assessed on the basis of testis length (mature $>6 \mathrm{~mm}$ ) and uterus size (mature $>1 \mathrm{~mm}$ ). The spleen and lungs were immediately placed in RNA Later (Sigma-Aldrich, St Louis, MO, USA) and stored at $-20^{\circ} \mathrm{C}$ for genetic analyses. Blood samples were collected from the heart onto a $1 \mathrm{~cm}^{2}$ Whatman blotting paper. We checked for PUUV immunoglobulin $\mathrm{G}$ antibodies in an indirect fluorescent antibody test (Kallio-Kokko et al., 2006). PUUV load was measured in the lungs of PUUV-seropositive voles, by realtime quantitative reverse transcriptase-PCR (primers: forward 5'-GAGGATATAACCCGCCATGA-3'; reverse $5^{\prime}$-CTGGCTTGCAGTGTGTTTTT-3') using a DyNAmo Capillary SYBR Green Quantitative PCR kit (Finnzymes, Vantaa, Finland) with a LightCycler instrument (Roche Diagnostics, Basel, Switzerland). Glyceraldehyde-3-phosphate dehydrogenase (GAPDH) was used as a housekeeping gene to normalize samples against variation in vole lung sample quality and quantity (primers: forward $5^{\prime}$-ATGGGGAAGGTGAAGGTCG-3' and reverse $5^{\prime}$-TAAAAGCAGCCCTGGTGACC- ${ }^{\prime}$ ). An absolute quantification of PUUV copy numbers (copies per $1 \mu \mathrm{g}$ of total RNA) was calculated from a standard curve created using 10-fold dilutions of in vitro transcribed PUUV S segment RNA (T7 transcription kit, Fermentas, Vilnius, Lithuania). Samples were considered PUUV RNA positive when the cycle threshold value was lower than 40 cycles (for more details, see Ribas Salvador et al., 2011).

Finally, we screened for the presence of the nematode H. mixtum in the gut of each individual by examination under a microscope. These data have been reported elsewhere (Ribas Salvador et al., 2011).

\section{Quantification of $\operatorname{Tnf}-\alpha$ and $M x 2$ gene expression}

For practical reasons, we quantified Tnf- $\alpha$ and $M x 2$ gene expression in a subset of 189 bank voles among the 308 trapped in the 10 sites sampled (seeSupplementary Table S1). This subsample included 33 PUUV-seropositive individuals. A subset of PUUV-seronegative individuals were next selected to 
reach about 20 voles per site of sampling (Boult-aux-bois and Briquenay with 11 and 9 voles, respectively, are only $3 \mathrm{~km}$ apart), with an equal sex ratio, so that we have a representative subsample of each site.

Total RNA was extracted from the spleen of bank voles by the TRIzol/ chloroform protocol recommended by the manufacturer (Invitrogen, Carlsbad, CA, USA). We chose to extract RNA from the spleen because this organ has important immune functions (it is a secondary lymphoid organ) and is the site of low levels of PUUV replication (Korva et al., 2009). Moreover, experimental studies that have followed the kinetics of immune gene expression in rodent hosts infected by hantaviruses all showed that the expression of Tnf- $\alpha$ gene remained unchanged in the spleen of infected rodents from the time of infection to 40 days post-infection or compared with uninfected ones (Easterbrook and Klein, 2008; Schountz et al., 2012; Spengler et al., 2013). Spleens therefore reflect the constitutive levels of $\operatorname{Tnf}-\alpha$ and $M \times 2$ expression, not influenced by PUUV infection but potentially modulated by other infections that should mainly be randomly distributed between PUUV-infected and PUUV-non-infected voles.

We used $\beta$-actin as the endogenous reference gene, as previously validated by Friberg et al. (2011) in wood mice. These authors tested a set of nine candidate housekeeping genes in cell cultures and concluded that $\beta$-actin was the most stable. We analyzed $\operatorname{Tnf}-\alpha$ gene expression by reverse transcriptase-PCR with the specific primers described in a previous study (Guivier et al., 2010b): Tnf-a-ex1-F (5'-TTCTGTCTGCTGAACTTCGGA-3 $\left.{ }^{\prime}\right)$ binding to exon 1 , Tnf-a-ex3-4-R ( $5^{\prime}$-GGGTTTGCTACAACGTGG- $\left.3^{\prime}\right)$ binding to exons 3 and 4; Actinb-ex3-F (5'-CTTCTACAACGAGCTGCG-3') binding to exon 3 and Actinb-ex4-R (5'-CCGGAGTCCATCACAAT- $\left.3^{\prime}\right)$ binding to exon 4 . We designed bank vole-specific $M \times 2$ primers. The universal primers MxUniv2-F (5'-CATTGACCTCATCGACTCCCTGCG-3') and MxUniv2-R (5'-GCCAGCT TAACCAGGGAATTTGG-3' ${ }^{\prime}$ ) were initially chosen, based on the available fulllength complementary DNA (cDNA) sequences for Rattus norvegicus (Transcript ID: ENSRNOT00000002695) and Mus musculus (Transcript ID: ENSMUST00000024112) in Ensembl. RNA samples from two bank voles were used as templates for cDNA synthesis. We generated cDNA from $2 \mu \mathrm{l}$ of extracted RNA (500 ng per reaction), in a $20 \mu \mathrm{l}$ reaction, with the Improm-II Reverse Transcription System (Promega, Madison, WI, USA), according to the conditions specified by the manufacturer for oligo (dT) 15 primers. PCR was performed on an EPgradient S MasterCycler (Qiagen, Venlo, Netherlands), in a final volume of $25 \mu$ l containing $1 \times$ Qiagen Multiplex PCR Kit, $0.2 \mu \mathrm{M}$ of each primer and $2 \mu \mathrm{l}$ of template cDNA diluted 1:5. Cycling conditions were as follows: initial denaturation at $95^{\circ} \mathrm{C}$ for $15 \mathrm{~min}$ followed by 40 cycles of denaturation at $94{ }^{\circ} \mathrm{C}$ for $30 \mathrm{~s}$, annealing at $50{ }^{\circ} \mathrm{C}$ for $30 \mathrm{~s}$ and elongation at $72^{\circ} \mathrm{C}$ for $60 \mathrm{~s}$ and a final extension phase at $72^{\circ} \mathrm{C}$ for $10 \mathrm{~min}$. Sequences for both strands were obtained for each sample (Eurofins MWG Synthesis GmbH, Ebersberg, Germany) with the MxUniv2-F and MxUniv2-R primers. Based on the cDNA consensus sequences obtained for these two M. glareolus samples (GenBank AN: JX183218), we designed the following specific primers: Mx2q2F ( $5^{\prime}$-TCAGAGAGAAGGAAGCCGA-3') and Mx2q2-R (5'-GAGATGCGGTTG TGAGC- $3^{\prime}$ ), binding to exons 13 and 14 , respectively, (amplicon size $142 \mathrm{bp}$ ).

Real-time PCR quantification was performed on a LightCycler 480 (Roche Diagnostics), using the 384-multiwell plate format to quantify $\operatorname{Tnf}-\alpha$ and $M x 2$ gene expression in our samples. For each vole and gene, three replicates were carried out. Details of the PCR conditions and of the method used to estimate the amounts of $T n f-\alpha$ and Mx2 RNA are provided elsewhere (Guivier et al., 2010b)

\section{Statistical methods}

TNF- $\alpha$ and Mx2 are well known to inhibit hantavirus replication in humans or cell lines exogenously stimulated with hantaviruses (Kanerva et al., 1996; Jin et al., 2001). We thus examined whether we could detect an effect of $\operatorname{Tnf}-\alpha$ and $M x 2$ constitutive gene expression (these genes do not seem to be upregulated in rodent spleen following hantavirus infection; Easterbrook and Klein, 2008; Schountz et al., 2012; Spengler et al., 2013) on PUUV replication in wild bank voles. We considered the data set including infected bank voles only $(N=33)$. We analyzed independently the effects of $\operatorname{Tnf}-\alpha$ or $M x 2$ gene expression levels on PUUV load using generalized linear models. The full models included PUUV load as the dependent variable and $\operatorname{Tnf}-\alpha$ (or $M \times 2)$ gene expression levels as explanatory variables. We took into account for the potential confounding influence of individual and environmental variables by including sexual maturity, sex and geographic area (northern 'massif des Ardennes' versus southern 'crêtes ardennaises') as potential explanatory factors. Owing to limited sample sizes (see Supplementary Table S1), we could not test the effect of population and of interactions between factors. Gene expression values $(\mathrm{Qn})$ and PUUV load were log-transformed to normalize their distributions. For both generalized linear models, all possible models were considered in the MuMIn package developed in R.2.13.1 software (R Development Core Team, 2008). We used the corrected Akaike Information Criterion (AICc) to select the most parsimonious model (Johnson and Omland, 2004). Models with a $\delta \mathrm{AICc}<2$ with respect to the model with the lowest AICc were selected. The significance of explanatory variables was determined by deletion testing, with the significance of a term determined by the log-likelihood ratio method (McCullagh and Nelder, 1989).

We next used a generalized linear model to analyze the impact of landscape on genetic immunoheterogeneity. The whole data set of 189 bank voles was included. We used the expression of Tnf- $\alpha$ or $M \times 2$ as the dependent variables. We considered the potential effects of habitat fragmentation (continuous forest versus hedge network) and geographic area ('massif des Ardennes' versus 'crêtes ardennnaises') separately. The complete models also included sex, sexual maturity and all two-way interactions (model 1: $\operatorname{Ln}(\operatorname{Tnf}-\alpha$ or $M x 2) \sim$ habitat ${ }^{*}$ sex $^{\star}$ sexual maturity and model $2: \operatorname{Ln}(\operatorname{Tnf}-\alpha$ or $M x 2) \sim$ geographic area $^{\star} \operatorname{sex}^{\star}$ sexual maturity). This made it possible to take into account potential interactions between reproductive status and immunity in both males and females. We applied the same model selection procedure as described above.

Finally, we investigated the potential immunomodulatory effect of H. mixtum infection on PUUV infection. We used the restricted data set for the northern 'massif des Ardennes' where we previously found a significant association between PUUV and H. mixtum (Ribas Salvador et al., 2011). Several studies on laboratory mice and wild rodents have shown that a phylogenetically closely related helminth species, Heligmosomoides polygyrus, may be immunosuppressive (Jackson et al., 2009; Maizels et al., 2012). This suggested that infection with $H$. mixtum might modulate the immune responses of bank voles and change their susceptibility to PUUV. We performed an analysis of variance on immune gene expression levels between four groups of animals differing in infectious status: uninfected individuals, individuals infected with PUUV only, individuals infected with $H$. mixtum only and individuals co-infected with PUUV and H. mixtum. We performed $a$ posteriori pairwise comparison analyses by the Tukey-Kramer method. All statistical analyses were performed with R.2.13.1 software ( $R$ Development Core Team, 2008).

\section{RESULTS}

Immune gene expression and Puumala virus replication

We were able to estimate PUUV load for 29 of the 33 infected voles. The other four individuals were excluded from the analyses because PUUV load was too low to be estimated. This data set was used to analyze PUUV load variability.

The model selection procedure indicated that the best model explaining PUUV load variability included Tnf- $\alpha$ gene expression level $\left(\mathrm{AICc}=130.9, \mathrm{~F}_{1,27}=9.66, P=0.004\right.$, Figure 1a, Supplementary Table S2) or $M \times 2$ gene expression level $\left(\mathrm{AICc}=132.9, \mathrm{~F}_{1,27}=7.21\right.$, $P=0.012$, Figure 1b, Supplementary Table S3). Tnf- $\alpha$ and $M \times 2$ gene expression levels negatively affected PUUV load. None of the individual (sex, sexual maturity) or environmental (geographic area) factors significantly influenced PUUV loads.

\section{Immune gene expression and landscape}

Further analyses were performed on the whole data set $(N=189)$. After selection procedure, the factors relative to landscape features were excluded and the best model included only the factor sex. Tnf- $\alpha$ gene was less expressed in males than in females $(\mathrm{AICc}=301.1$, $\mathrm{F}_{1,188}=5.37, P=0.021$, Figure 2, Supplementary Table S4). 

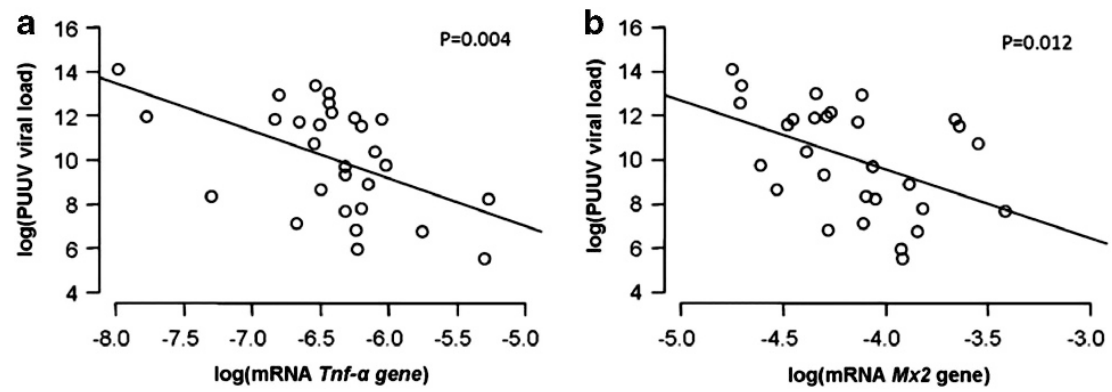

Figure 1 Negative relationship between PUUV load and Tnf- $\alpha$ (a) or $M \times 2(\mathbf{b})$ gene expression levels $(N=29)$. P-values (F test statistics) are indicated.

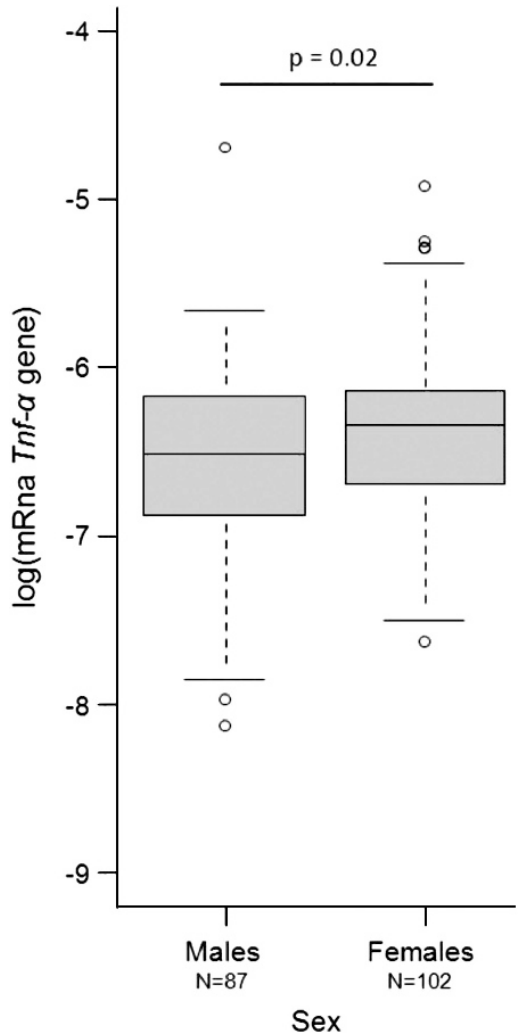

Figure 2 Difference in Tnf- $\alpha$ expression level between sexes is shown for PUUV individuals $(N=189)$. Grey boxes represent the first and third quartiles of the distribution. Horizontal black lines correspond to medians. The vertical dashed lines correspond to 1.5 times the interquartile range. The circles represent the values outside the range corresponding to 1.5 times the interquartile range.

Considering Mx2 gene, one sample could not be included in the analyses because of an unsuccessful estimation of its expression. At the end of the selection procedure, the best model included the factors habitat and sexual maturity $\left(\mathrm{AICc}=286.7, \mathrm{~F}_{2,187}=12.77, P<0.001\right.$, Supplementary Table S5). Bank voles from forests had lower levels of $M \times 2$ gene expression than voles living in fragmented hedge networks $\left(F_{1,188}=9.41, P=0.002\right.$, Figure 3a). Sexually mature voles had higher levels of $M \times 2$ gene expression than immature voles $\left(\mathrm{F}_{1,154}=14.49\right.$, $P<0.001$, Figure 3b).

Effect of $\boldsymbol{H}$. mixtum infection on immune gene expression Analyses were performed on the restricted data set of animals from the northern 'massif des Ardennes' $(N=66)$ because we previously detected a significant association between $H$. mixtum and PUUV.
Analysis of variance showed a significant difference in $\operatorname{Tnf}-\alpha$ gene expression levels between the four groups of animals defined on the basis of infection status $\left(\mathrm{F}_{3,63}=6.5, P<0.001\right)$. A posteriori pairwise comparisons showed that individuals infected with PUUV only had significantly higher levels of $\operatorname{Tnf}-\alpha$ gene expression than uninfected individuals $(P=0.018$, Figure 4$)$, individuals infected with $H$. mixtum only $(P=0.011$, Figure 4$)$ and co-infected voles $(P=0.001$, Figure 4$)$. None of the other comparisons were significant $(P>0.05)$, but voles only infected with $H$. mixtum exhibited lower Tnf- $\alpha$ gene expression than uninfected voles or voles co-infected with $H$. mixtum and PUUV.

We found no significant difference in $M x 2$ gene expression between the animals of the four groups $\left(\mathrm{F}_{3,61}=6.5, P=0.10\right)$.

\section{DISCUSSION}

Association between the expression of $\operatorname{Tnf}-\alpha$ or $M x 2$ and PUUV load in bank voles

This study showed, for the first time, that the expression of Tnf- $\alpha$ and Mx2 is associated with a lower PUUV load in wild bank voles, independently of some individual (sex, maturity) and geographic (North versus South of the area) factors. The expression of these genes was quantified in the spleen, a secondary lymphoid organ in which hantavirus replication rates are low (for example, Botten et al., 2000) and Tnf- $\alpha$ gene expression is not induced in response to hantavirus infection (Easterbrook and Klein, 2008; Guivier et al., 2010b; Schountz et al., 2012, Spengler et al., 2013). This probably reflects the presence of macrophages constitutively expressing the Tnf$\alpha$ gene (Hutchinson et al., 1998; Herbst et al., 2002). Similarly, Stoltz et al. (2011) showed that PUUV did not induce an increase in Mx2 mRNA production in bank vole embryonic fibroblasts. The relation observed in this study therefore does not result from differences in the duration since infection between bank voles. It is also not indirectly mediated by differences in vole age, sex or populations. Besides, studies based on clinical cases or cell cultures have shown that the TNF- $\alpha$ and Mx2 proteins inhibit hantavirus replication (Kanerva et al., 1996; Khaiboullina et al., 2000; Jin et al., 2001). The strong negative effects of Tnf- $\alpha$ or $M x 2$ expression levels on PUUV load therefore indicate that these proinflammatory and antiviral pathways are important components of the constitutive vole response to PUUV infection.

The maintenance of some variability in the expression of these genes may at first appear strange, given the clear advantages of TNF- $\alpha$ and $\mathrm{Mx} 2$ in the response to PUUV and other infections. We proposed that the variability observed reflects the balance between the costs of these immune effectors (in terms of energy and/or immunopathological damages) and their benefits in term of PUUV elimination. We further explored several intrinsic and environmental factors that might contribute to the maintenance of this immunoheterogeneity. 

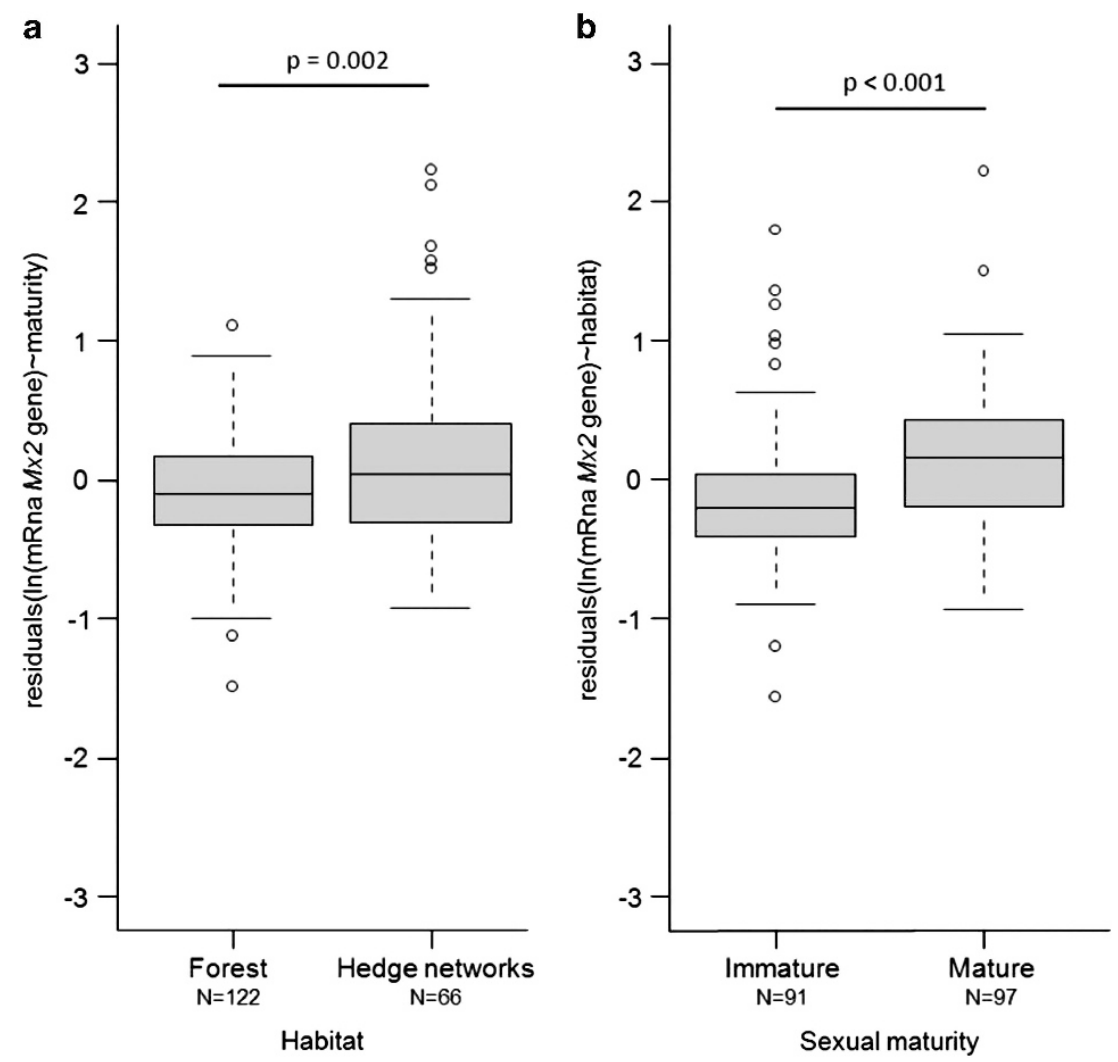

Figure 3 Effect of habitat (a) and sexual maturity status (b) on the variability of $M x 2$ expression level in PUUV voles $(N=188)$. One individual could not be included in the analyses because of an absence of $M \times 2$ data.

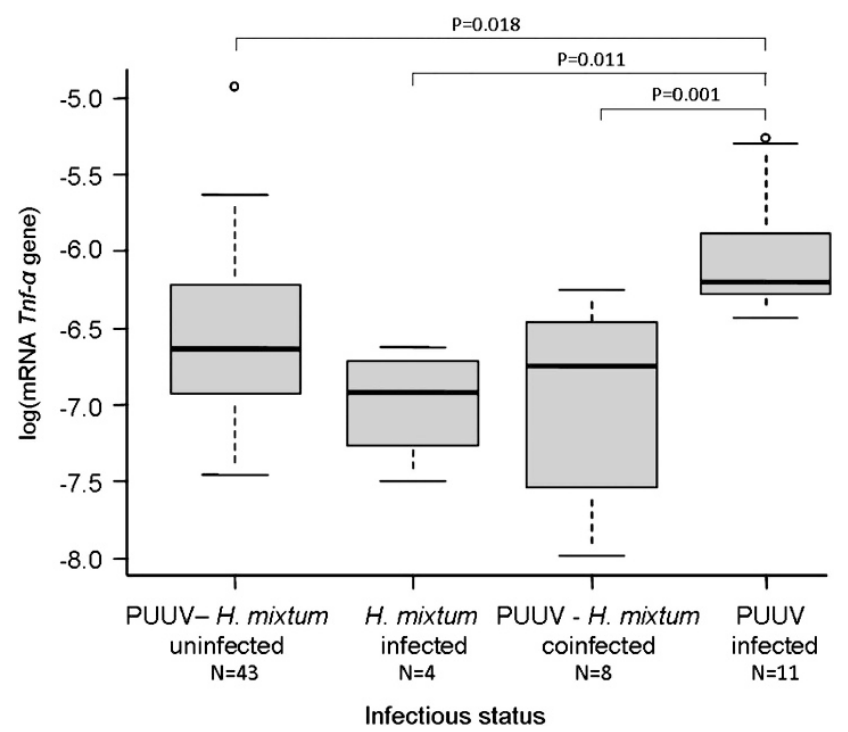

Figure 4 Variability of Tnf-a expression in wild bank vole populations from the northern 'massif des Ardennes' $(N=66)$ as a function of infection status: uninfected individuals (infected with neither $H$. mixtum nor PUUV), individuals infected with $H$. mixtum only, individuals infected with PUUV only and individuals co-infected with $H$. mixtum and PUUV. Significant pairwise comparisons based on the Tukey-Kramer test are shown.

\section{Intrinsic factors shaping immunoheterogeneity}

We found that males had significantly lower levels of Tnf- $\alpha$ expression than females. In addition, levels of $M \times 2$ expression were significantly lower in sexually immature than in mature voles. These differences are consistent with the existence of intrinsic constraints modulating immune gene expression (Sheldon and Verhulst, 1996). Sexual dimorphism in the immune response to hantaviruses has been reported before. During experimental infections with Seoul hantavirus in Norway rats (Rattus norvegicus), females have been shown to express Tnf- $\alpha$ and $M x$ more strongly than males (Klein et al., 2004). This sexual dimorphism is mainly influenced by hormonal status and genetic trade-offs between testosterone production and immune functions (Klein, 2005).

These results also give new insights into the epidemiology of PUUV infections in wild bank vole populations. Differences have commonly been observed in PUUV incidence, with males (Olsson et al., 2002; Deter et al., 2008a) and mature bank voles (for example, Escutenaire et al., 2002) more frequently infected than females and immature ones. Behavioral and physiological characteristics participate in shaping these differences. Protection of newborns by maternal antibodies and higher risk of exposure for sexually mature voles through fighting, mating or communal nesting (Escutenaire et al., 2002; Olsson et al., 2002) could mediate age-dependent prevalence. Our results suggest that individual variations of immune gene expression could reinforce these differences in the epidemiological roles of particular bank vole groups within natural populations. In particular, males, through higher capacities to replicate, excrete PUUV, and to perform long-distance dispersal (Kozakiewicz et al., 2007), could have key roles in spreading PUUV within the landscape (Deter et al., 2008a; Voutilainen et al., 2012). The lower expression of Mx2 gene detected in immature voles could also have important epidemiological consequences for PUUV transmission. In particular 
in autumn, at the end of the breeding season, bank vole populations are made up of a high proportion of immature individuals. This could contribute to higher levels of PUUV prevalence observed in the environment during this period. Investigating temporal fluctuations of individual immunoheterogeneity through seasons and pluri-annual cycles of densities would be a further step to better understand the influence of immune gene expression variation on PUUV epidemiology.

\section{Environmental conditions and co-infection shaping immunoheterogeneity in the landscape}

The levels of Tnf- $\alpha$ and $M x 2$ expression both varied with the landscape features through the effect of habitat fragmentation and with co-infection. The immune gene $M \times 2$ was less strongly expressed in forests than in hedges. Abiotic and biotic factors may participate in modulating bank vole population immunoheterogeneity within this heterogeneous landscape. Variability in habitat patch quality may also contribute to the observed immunoheterogeneity. Low resource availability and stress because of competition or predation probably affect the ability of hosts to mount efficient immune responses (Beldomenico et al., 2008; Martin et al., 2008). Hedges are thought to be lower quality habitats for bank voles than large continuous forests, particularly in terms of the presence of food-producing plants and trees (Heyman et al., 2009). We therefore expected levels of Tnf- $\alpha$ and Mx2 gene expression to be lower in bank vole populations from the hedges or from the 'crêtes ardennaises', which consist largely of hedge networks. However, the opposite pattern or an absence of relation were detected for Mx2 and Tnf- $\alpha$ gene. Similarly, Jackson et al. (2011) showed that wild field voles with a poorer body condition were characterized by a higher levels of proinflammatory cytokine expression. They suggested that other undetermined environmental drivers, pathogens or immunopathological conditions might account for this unexpected result.

Variation in parasite communities is a component of habitat heterogeneity that might indirectly shape the spatial immunoheterogeneity described in this study. Within-host co-infections modulate immune responses through complex interactions between cytokines and between these molecules and other immune effectors that may lead to immunosuppression or cross-immunity (Graham et al., 2007). The $\mathrm{Mx} 2$ protein has innate selective antiviral activity in the cytoplasm of host cells (for example, Stertz et al., 2007), so the observed variation in $M \times 2$ gene expression could result from differences in the community of viruses living in forests and hedges, which remain to be investigated. TNF- $\alpha$ is a nonspecific immune protein. It may therefore appear a challenge to detect the environmental factors, particularly associated with pathogen communities, influencing Tnf- $\alpha$ variation. However, a previous study showed that the structure of the gastrointestinal helminth community of bank voles displayed geographic differentiation between the 'massif des Ardennes' and the 'crêtes ardennaises' (Ribas Salvador et al., 2011). The distribution of helminth species may, therefore, at least partly underlie the variation of $\operatorname{Tnf}-\alpha$ expression.

Immunopathological costs may also be involved in this spatial immunoheterogeneity. TNF- $\alpha$ and $\mathrm{Mx} 2$ are costly immune effectors inducing collateral damage when present at high concentration $(\mathrm{Li}$ and Youssoufian, 1997; Wenzel et al., 2005; Porter et al., 2006; Bradley, 2008). Lower levels of expression of the genes encoding these molecules may therefore be considered to constitute a tolerance mechanism, an adaptive process limiting pathologies at the expense of pathogen growth or reproduction (Raberg et al., 2009). The variability of immune gene expression may result at least in part from individual plastic responses to the various constraints encountered by bank voles (for example, sexual maturation, risks and costs of infection). Furthermore, both selection and neutral microevolutionary forces may trigger this variability. Indeed, some polymorphisms in the promoter of Tnf- $\alpha$ (Kroeger et al., 1997; Maes et al., 2006; Borges et al., 2010), Mx2 (Tungtrakoolsub et al., 2008) genes or in interferonstimulated response element-like sequences (Asano et al., 2003) have been shown to influence the regulation of $\operatorname{Tnf}-\alpha$ or $M x 2$ transcription. The maintenance and distribution of these polymorphisms may underlie the observed inter-individual variation in the expression of these two genes.

In fragmented landscapes, metapopulation dynamics is a main determinant of the spatiotemporal distribution of neutral and adaptive polymorphism. Guivier et al. (2011) recently highlighted the effect of landscape heterogeneity on bank vole metapopulation dynamics in this geographic area. They concluded that local adaptation was likely to evolve in large populations living in forests, which are characterized by weak genetic drift. By contrast, the strong genetic drift occurring in small, isolated populations living in hedge networks should impede the effects of selective processes acting on immune genes. The lower levels of expression of the $M \times 2$ gene detected in the populations from large forests may be due to selective processes. Unlike hedges, forests seem to provide conditions favoring the persistence of PUUV outside its host (Kallio et al., 2006). We can therefore hypothesize that these selective processes have led to the evolution of higher tolerance to PUUV in forests. Unfortunately, it was not possible, in this empirical study, to separate the relative contributions of genetics and environmental background to immune gene expression levels. Further investigations in controlled environments or involving reciprocal transfers between habitat patches are required to determine the relative importance of plasticity and selection in the expression of the Tnf- $\alpha$ and $M \times 2$ genes, and their role in potential resistance/tolerance to PUUV.

\section{Epidemiological consequences for PUUV infection}

Finally, our results highlight the potential immunological interactions mediated by helminth-PUUV co-infections in the 'massif des Ardennes'. Voles co-infected with PUUV and H. mixtum had levels of Tnf- $\alpha$ expression similar to those of voles infected with neither PUUV nor $H$. mixtum. In addition, PUUV-infected voles displayed significantly higher levels of Tnf- $\alpha$ expression than co-infected and uninfected voles. This corroborates previous results which showed that bank voles co-infected with $H$. mixtum tended to exhibit higher PUUV loads than bank voles infected by PUUV 'only' (Ribas Salvador et al., 2011). Several helminth species are known to manipulate the host immune system directly, through derived products activating T-regulatory cells, which decrease the inflammatory response (Maizels et al., 2004). In particular, Heligmosomoïdes polygyrus bakeri has been shown to induce a wide spectrum of immunomodulatory effects in the laboratory mouse and to affect the outcome of infection with several pathogens, including nematodes, trematodes, protozoa and bacteria (see a recent review by Maizels et al., 2012). Jackson et al. (2009) even showed, in wild wood mice (Apodemus sylvaticus), that the Tnf- $\alpha$ response to TLR ligands was downregulated by natural infection with $H$. polygyrus. It has been suggested that $H$. mixtum may also be immunosuppressive. Consistent with this hypothesis, the pattern observed in this study suggests that $H$. mixtum infection could downregulate $T n f-\alpha$ expression in bank voles, rendering PUUV replication faster and more efficient. This interaction may underlie the positive association previously observed between $H$. mixtum and PUUV (Ribas Salvador et al., 2011). At a larger scale, it would be 
interesting to investigate the impact of the spatial distribution and temporal dynamics of H. mixtum (Haukisalmi and Henttonen, 1993) on the risk of PUUV infection in bank voles.

\section{PERSPECTIVES}

Landscape immunogenetics - the study of immune gene variability between landscapes and its causes_-provides key information about parasite epidemiology and 'pathogenic landscapes', as proposed by Lambin et al. (2010). We identified several landscape features (habitat quality, metapopulation dynamics) and helminth co-infection that may participate in shaping immunoheterogeneity in wild host populations. More detailed investigations of the whole pathogen communities infecting these bank voles are now possible from the development of new generation sequencing technologies and metagenomic analyses. These approaches have yet allowed to describe microbial communities and to explore their interactions in different hosts' organs or environments (Nakamura et al. 2008; Carpi et al., 2011; Cheval et al., 2011). In the future, the integration of such information in the analysis of PUUV epidemiology will provide a better understanding of the impacts of co-infection on the evolution of tolerance to PUUV in bank voles.

\section{DATA ARCHIVING}

Data deposited in the Dryad repository: doi: 10.5061/dryad.80629.

\section{CONFLICT OF INTEREST}

The authors declare no conflict of interest.

\section{ACKNOWLEDGEMENTS}

We thank Y Chaval, A Xuereb, ML Poulle for assistance with fieldwork, A Ribas Salvador for helminth identification, T Sironen and L Voutilainen for previous PUUV analyses. This study was partly funded by the European programs GOCE-CT-2003-010284 EDEN and FP7-261504 EDENext. This article is registered with the EDENext Steering Committee as EDENext060 (http://www. edenext.eu/).

Asano A, Jin HK, Watanabe T (2003). Mouse Mx2 gene: organization, mRNA expression and the role of the interferon-response promoter in its regulation. Gene 306: 105-113.

Beldomenico PM, Telfer S, Gebert S, Lukomski L, Bennett M, Begon M (2008). Poor condition and infection: a vicious circle in natural populations. Proc $R$ Soc London Ser B 275: 1753-1759.

Bocher A, Tirard C, Doums C (2007). Phenotypic plasticity of immune defence linked with foraging activity in the ant Cataglyphis velox. J Evol Biol 20: 2228-2234.

Bordes F, Morand S (2009). Coevolution between multiple helminth infestations and basal immune investment in mammals: cumulative effects of polyparasitism? Parasitol Res 106: 33-37.

Borges AA, Donadi EA, Campos GM, Moreli ML, de Sousa RLM, Saggioro FP et al. (2010), Association of-308G/A polymorphism in the tumor necrosis factor-alpha gene promoter with susceptibility to development of hantavirus cardiopulmonary syndrome in the Ribeiro Preto region, Brazil. Arch Virol 155: 971-975.

Botten J, Mirowsky K, Kusewitt D, Bharadwaj M, Yee J, Ricci R et al. (2000). Experimental infection model for Sin Nombre hantavirus in the deer mouse (Peromyscus maniculatus). Proc Natl Acad Sci USA 97: 10578-10583.

Bradley JR (2008). TNF-mediated inflammatory disease. J Pathol 214: 149-160.

Carpi G, Cagnacci F, Wittekindt NE, Zhao F, Qi J, Tomsho LP et al. (2011). Metagenomic profile of the bacterial communities associated with Ixodes ricinus ticks. PLoS One 6 e25604.

Cheval J, Sauvage V, Frangeul L, Dacheux L, Guigon G et al. (2011). Evaluation of highthroughput sequencing for identifying known and unknown viruses in biological samples. J Clin Microbiol 49: 3268-3275.

Cotter SC, Kruuk LE, Wilson K (2004). Costs of resistance: genetic correlations and potential trade-offs in an insect immune system. J Evol Biol 17: 421-429.

Cox FE (2001). Concomitant infections, parasites and immune responses. Parasitol 122 S23-S38.

Deter J, Chaval Y, Galan M, Gauffre B, Morand S, Henttonen H et al. (2008a). Kinship, dispersal and hantavirus transmission in bank and common voles. Arch Virol 153 435-444.
Deter J, Chaval Y, Galan M, Henttonen H, Laakkonen J, Voutilainen L et al. (2008b). Association between the DQA MHC class II gene and Puumala virus infection in the specific reservoir Myodes glareolus. Infect Genet Evol 8: 450-458.

Easterbrook JD, Klein SL (2008). Seoul virus enhances regulatory and reduces proinflammatory responses in male Norway rats. J Med Virol 80: 1308-1318.

Escutenaire S, Chalon P, de Jaegere F, Karelle-Bui L, Mees G, Brochier B et al. (2002). Behavioral, physiologic, and habitat influences on the dynamics of Puumala virus infection in bank voles (Clethrionomys glareolus). Emerg Infect Dis 8: 930-936.

Friberg IM, Lowe A, Ralli C, Bradley JE, Jackson JA (2011). Temporal anomalies in mmunological gene expression in a time series of wild mice: signature of an epidemic? PLoS One 6: e20070.

Graham AL (2008). Ecological rules governing helminth-microparasite co-infection. Proc Natl Acad Sci USA 105: 566-570.

Graham AL, Cattadori IM, Lloyd-Smith JO, Ferrari MJ, Bjornstad ON (2007). Transmission consequences of co-infection: cytokines writ large? Trends Parasitol 23: 284-291.

Guivier E, Galan M, Chaval Y, Xuereb A, Ribas Salvador A, Poulle ML et al. (2011). Landscape genetics highlights the role of bank vole metapopulation dynamics in the epidemiology of Puumala hantavirus. Mol Ecol 20: 3569-3583.

Guivier E, Galan M, Male PJG, Kallio ER, Voutilainen L, Henttonen H et al. (2010a). Associations between $\mathrm{MHC}$ genes and Puumala virus infection in Myodes glareolus are detected in wild populations, but not from experimental infection data. J Gen Viro/ 91 2507-2512.

Guivier E, Galan M, Ribas Salvador A, Xuéreb A, Chaval Y, Olsson G et al. (2010b). Tnf- $x$ expression and promoter sequences reflect the balance of tolerance/resistance to Puumala virus infection in European bank vole populations. Infect Genet Evol 10 1208-1217.

Hardestam J, Karlsson M, Falk KI, Olsson G, Klingstrom J, Lundkvist A (2008). Puumala hantavirus excretion kinetics in bank voles (Myodes glareolus). Emerg Infect Dis 14 1209-1215.

Haukisalmi V, Henttonen H (1993). Coexistence in helminths of the bank vole Clethrionomys glareolus. II. Intestinal distribution and interspecific interactions. J Anim Ecol 62: 230.

Herbst MM, Prescott J, Palmer ADN, Schountz T (2002). Sequence and expression analysis of deer mouse interferon-gamma, interleukin-10, tumor necrosis factor, and lymphotoxin-alpha. Cytokine 17: 203-213

Heyman P, Van Mele R, Smajlovic L, Dobly A, Cochez C, Vandenvelde C (2009). Association between habitat and prevalence of hantavirus infections in bank voles (Myodes glareolus) and wood mice (Apodemus sylvaticus). Vector Borne Zoonotic Dis 9: 141-146.

Hutchinson KL, Rollin PE, Peters CJ (1998). Pathogenesis of a North American hantavirus, Black Creek Canal virus, in experimentally infected Sigmodon hispidus. Am J Trop Med Hyg 59: 58-65.

Jackson JA, Begon M, Birtles R, Paterson S, Friberg IM, Hall A et al. (2011). The analysis of immunological profiles in wild animals: a case study on immunodynamics in the field vole, Microtus agrestis. Mol Ecol 20: 893-909.

Jackson JA, Friberg IM, Bolch L, Lowe A, Ralli C, Harris PD et al. (2009). Immunomodulatory parasites and Toll-like receptor-mediated tumour necrosis factor alpha responsiveness in wild mammals. BMC Biol 7: 16.

Jin HK, Yoshimatsu K, Takada A, Ogino M, Asano A, Arikawa J et al. (2001). Mouse Mx2 protein inhibits hantavirus but not influenza virus replication. Arch Virol 146: $41-49$.

Johnson JB, Omland KS (2004). Model selection in ecology and evolution. Trends Eco Evol 19: 101-108.

Kallio ER, Klingstrom J, Gustafsson E, Manni T, Vaheri A, Henttonen $\mathrm{H}$ et al. (2006). Prolonged survival of Puumala hantavirus outside the host: evidence for indirect transmission via the environment. J Gen Virol 87: 2127-2134

Kallio-Kokko H, Laakkonen J, Rizzoli A, Tagliapietra V, Cattadori I, Perkins SE et al. (2006). Hantavirus and arenavirus antibody prevalence in rodents and humans in Trentino, Northern Italy. Epidemiol Infect 134: 830-836.

Kamal SM, El Sayed Khalifa K (2006). Immune modulation by helminthic infections: worms and viral infections. Parasite Immunol 28: 483-496.

Kanerva M, Melen K, Vaheri A, Julkunen I (1996). Inhibition of Puumala and Tula hantaviruses in vero cells by MxA protein. Virol 224: 55-62.

Khaiboullina SF, Netski DM, Krumpe P St, Jeor SC (2000). Effects of tumor necrosis factor alpha on Sin Nombre virus infection in vitro. J Virol 74: 11966-11971.

Kidd P (2003). Th1/Th2 balance: the hypothesis, its limitations, and implications for health and disease. Altern Med Rev 8: 223-246.

Klein SL (2005). Host factors mediating sex differences in viral infection. Gend Med 2 197-207.

Klein SL, Cernetich A, Hilmer S, Hoffman EP, Scott AL, Glass GE (2004). Differential expression of immunoregulatory genes in male and female Norway rats following infection with Seoul virus. J Med Virol 74: 180-190.

Knowles SC (2011). The effect of helminth co-infection on malaria in mice: a metaanalysis. Int J Parasitol 41: 1041-1051.

Koopman MM, Carstens BC (2011). The microbial phyllogeography of the carnivorous plant Sarracenia alata. Microb Ecol 61: 750-758.

Korva M, Duh D, Saksida A, Trilar T, Avsic-Zupanc T (2009). The hantaviral load in tissues of naturally infected rodents. Microb Infect 11: 344-351.

Kozakiewicz M, Chołuj A, Kozakiewicz A (2007). Long-distance movements of individuals in a free-living bank vole population: an important element of male breeding strategy. Acta Theriol 52: 339-348.

Kroeger KM, Carville KS, Abraham LJ (1997). The -308 tumor necrosis factor-alpha promoter polymorphism effects transcription. Mol Immunol 34: 391-399. 
Lambin EF, Tran A, Vanwambeke SO, Linard C, Soti V (2010). Pathogenic landscapes: interactions between land, people, disease vectors, and their animal hosts. Int $\mathrm{J}$ Health Geogr 9: 54.

Lazzaro BP, Little TJ (2009). Immunity in a variable world. Philos Trans R Soc B-Biol Sci 364: 15-26.

Li YL, Youssoufian H (1997). MxA overexpression reveals a common genetic link in four Fanconi anemia complementation groups. J Clinic Invest 100: 2873-2880.

Maes P, Clement J, Groeneveld PHP, Colson P, Huizinga TWJ, Van Ranst M (2006). Tumor necrosis factor-alpha genetic predisposing factors can influence clinical severity in nephropathia epidemica. Viral Immunol 19: 558-564.

Maizels RM, Balic A, Gomez-Escobar N, Nair M, Taylor MD, Allen JE (2004). Helminth parasites - masters of regulation. Immunol Rev 201: 89-116.

Maizels RM, Hewitson JP, Murray J, Harcus YM, Dayer B, Filbey KJ et al. (2012). Immune modulation and modulators in Heligmosomoides polygyrus infection. Exp Parasitol 132: 76-89.

Makela S, Mustonen J, Ala-Houhala I, Hurme M, Partanen J, Vapalahti O et al. (2002). Human leukocyte antigen-B8-DR3 is a more important risk factor for severe Puumala hantavirus infection than the tumor necrosis factor-alpha(-308) G/A polymorphism. $\mathrm{J}$ Infect Dis 186: 843-846.

Martin LB, Weil ZM, Nelson RJ (2008). Seasonal changes in vertebrate immune activity: mediation by physiological trade-offs. Philos Trans R Soc B-Biol Sci 363: 321-339.

McCullagh P, Nelder JA (1989). Generalised Linear Models, 2nd edn edn: London, UK.

Meyer BJ, Schmaljohn CS (2000). Persistent hantavirus infections: characteristics and mechanisms. Trends Microbiol 8: 61-67.

Mills JN, Childs J, Ksiazek TG, Peters CJ, Velleca WM (1995). Methods for Trapping and Sampling Small Mammals for Virologic Testing. Centers for Disease Control and Prevention: Atlanta.

Nakamura S, Maeda N, Miron IM, Yoh M, Izutsu K et al. (2008). Metagenomic diagnosis of bacterial infections. Emerg Infect Dis 14: 1784-1786.

Olsson GE, White N, Ahlm C, Elgh F, Verlemyr AC, Juto P et al. (2002). Demographic factors associated with hantavirus infection in bank voles (Clethrionomys glareolus). Emerg Infect Dis 8: 924-929.

Pathak AK, Pelensky C, Boag B, Cattadori IM (2012). Immuno-epidemiology of chronic bacterial and helminth co-infections: observations from the field and evidence from the laboratory. Int J Parasitol 42: 647-655.

Plyusnin A, Horling J, Kanerva M, Mustonen J, Cheng Y, Partanen J et al. (1997). Puumala hantavirus genome in patients with nephropathia epidemica: correlation of PCR positivity with HLA haplotype and link to viral sequences in local rodents. J Clin Microbiol 35: 1090-1096.

Porter BF, Ambrus A, Storts RW (2006). Immunohistochemical evaluation of Mx protein expression in canine encephalitides. Vet Pathol 43: 981-987.

R Development Core Team. (2008). R: A language and environment for statistical computing. Vienna, Austria: The R Project for Statistical Computing Retrieved from (http://www.R-project.org).

Raberg L, Graham AL, Read AF (2009). Decomposing health: tolerance and resistance to parasites in animals. Philos Trans R Soc B-Biol Sci 364: 37-49.

Rantala MJ, Viitaniemi H, Roff DA (2011). Effects of inbreeding on potential and realized immune responses in Tenebrio molitor. Parasitol 138: 906-912.

Ribas Salvador A, Guivier E, Xuereb A, Chaval Y, Cadet P, Poulle ML et al. (2011). Concomitant influence of helminth infection and landscape on the distribution of Puumala hantavirus in its reservoir, Myodes glareolus. Bmc Microbiol 11: 30.
Schmid-Hempel $P$ (2003). Variation in immune defence as a question of evolutionary ecology. Proc R Soc London Ser B 270: 357-366

Schonrich G, Rang A, Lutteke N, Raftery MJ, Charbonnel N, Ulrich RG (2008). Hantavirus-induced immunity in rodent reservoirs and humans. Immunol Rev 225: 163-189.

Schountz T, Acuna-Retamar M, Feinstein S, Prescott J, Torres-Perez F, Podell B et al. (2012). Kinetics of immune responses in deer mice experimentally infected with $\mathrm{Sin}$ Nombre Virus. J Virol 86: 10015-10027.

Schulenburg H, Kurtz J, Moret Y, Siva-Jothy MT (2009). Introduction. Ecological immunology. Philos Trans R Soc B-Biol Sci 364: 3-14.

Sheldon BC, Verhulst S (1996). Ecological immunology: costly parasite defences and trade-offs in evolutionary ecology. Trends Ecol Evol 11: 317-321.

Spengler JR, Haddock E, Gardner D, Hjelle B, Feldmann H, Prescott J (2013). Experimental Andes Virus infection in deer mice: characteristics of infection and clearance in a heterologous rodent host. PLoS One 8: e55310.

Stertz S, Dittmann J, Blanco JCG, Pletneva LM, Haller O, Kochs G (2007). The antiviral potential of interferon-induced cotton rat $\mathrm{mx}$ proteins against orthomyxovirus (influenza), rhabdovirus, and bunyavirus. J Interf Cytok Res 27: 847-855.

Stoltz M, Sundstrom KB, Hidmark A, Tolf C, Vene S, Ahlm C et al. (2011). A model system for in vitro studies of bank vole borne viruses. PLoS One 6: 12

Temonen M, Mustonen J, Helin H, Pasternack A, Vaheri A, Holthofer H (1996). Cytokines, adhesion molecules, and cellular infiltration in nephropathia epidemica kidneys: an immunohistochemical study. Clin Immunol Immunopathol 78: 47-55.

Terajima M, Vapalahti O, Van Epps HL, Vaheri A, Ennis FA (2004). Immune responses to Puumala virus infection and the pathogenesis of nephropathia epidemica. Microb Infect 6: 238-245.

Tersago K, Crespin L, Verhagen R, Leirs H (2012). Impact of Puumala virus infection on maturation and survival in bank voles: a capture-mark-recapture analysis. J Wildlife Dis 48: $148-156$.

Tungtrakoolsub P, Noda T, Morozumi T, Hamasima N, Kobayashi E, Ueda J et al. (2008). Polymorphisms in the promoter region of the porcine antiviral MX1 and MX2 genes. Anim Genet 39: 22-27.

Vapalahti O, Mustonen J, Lundkvist A, Henttonen H, Plyusnin A, Vaheri A (2003). Hantavirus infections in Europe. Lancet Infect Dis 3: 653-661.

Voutilainen L, Savola S, Kallio ER, Laakkonen J, Vaheri A, Vapalahti 0 et al. (2012). Environmental change and disease dynamics: effects of intensive forest management on Puumala hantavirus infection in boreal bank vole populations. PLoS One 7: e39452.

Wenzel J, Worenkamper E, Freutel S, Henze S, Haller O, Bieber T et al. (2005). Enhanced type I interferon signalling promotes Th1-biased inflammation in cutaneous lupus erythematosus. J Pathol 205: 435-442.

Whitehorn PR, Tinsley MC, Brown MJ, Darvill B, Goulson D (2011). Genetic diversity, parasite prevalence and immunity in wild bumblebees. Proc $R$ Soc London Ser B 278: 1195-1202.

Woolhouse ME, Webster JP, Domingo E, Charlesworth B, Levin BR (2002). Biological and biomedical implications of the co-evolution of pathogens and their hosts. Nat Genet 32: 569-577.

Yanagihara R, Amyx HL, Gajdusek DC (1985). Experimental infection with Puumala virus, the etiologic agent of nephropathia epidemica, in bank voles (Clethrionomys glareolus). J Virol 55: 34-38.

Supplementary Information accompanies this paper on Heredity website (http://www.nature.com/hdy) 